\title{
Mineralización del nitrógeno, carbono y actividad enzimática del suelo en un bosque de Nothofagus obliqua (Mirb) Oerst y una plantación de Pinus radiata D. Don. del centro-sur de Chile
}

\author{
Nitrogen and carbon mineralization and enzyme activity in soils of Nothofagus obliqua \\ (Mirb) Oerst stands and Pinus radiata D. Don plantation in south-central Chile \\ YESSICA RIVAS ${ }^{1,}$ *, CARLOS OYARZÚN ${ }^{2}$, ROBERTO GODOY $^{1} \&$ EDUARDO VALENZUELA $^{3}$

\footnotetext{
${ }^{1}$ Instituto de Botánica, Facultad de Ciencias, Universidad Austral de Chile, Casilla 567, Valdivia, Chile ${ }^{2}$ Instituto de Geociencias, Facultad de Ciencias, Universidad Austral de Chile, Casilla 567, Valdivia, Chile

${ }^{3}$ Instituto de Microbiología, Facultad de Ciencias, Universidad Austral de Chile, Casilla 567, Valdivia, Chile *e-mail para correspondencia: yessicarivas@uach.cl
}

\begin{abstract}
RESUMEN
En Chile, el establecimiento de plantaciones comerciales de rápido crecimiento ha sido sostenido en las últimas décadas mediante la sustitución de bosques nativos y conversión de suelos agrícolas. Pinus radiata D. Don es la principal especie productiva, debido a su crecimiento acelerado y adaptabilidad al clima y los suelos. En el presente estudio se plantea que la actividad biológica del suelo es variable a través del año, en respuesta a variaciones de precipitación, temperatura y contenido de humedad de suelo y que el cambio de uso de suelo desde un bosque templado de Nothofagus obliqua (Mirb) Oerst a una plantación con coníferas exóticas, modifica la química del suelo y consecuentemente los procesos de N-min, C-min y la actividad biológica del suelo. Esta hipótesis fue examinada en un bosque de $N$. obliqua y una plantación de $P$. radiata del centro-sur de Chile $\left(40^{\circ} 07^{\prime} \mathrm{S}, 72^{\circ} \mathrm{O}\right)$. Se evaluó mensualmente la tasa mineralización de nitrógeno ( $\mathrm{N}$-min), cabono (C-min) y la actividad enzimática potencial del suelo (ureasa, proteasa e hidrólisis de la fluoresceína diacetato) entre septiembre 2003 y mayo 2005. Los resultados demuestran que los niveles de las variables de actividad biológica del suelo fueron significativamente diferentes entre las parcelas de bosque y plantación (Lambda de Wilk $=$ 0,$022 ; \mathrm{F}_{5,80}=733 ; \mathrm{P}<0,0001$ ) y entre los meses (Lambda de Wilk $=2,01 \mathrm{E}-6 ; \mathrm{F}_{100,395}=84 ; \mathrm{P}<0,0001$ ), siendo la actividad biológica mayor en el suelo de bosque de $N$. obliqua que en la plantación de $P$. radiata. Las tasas de $\mathrm{N}$-min y C-min presentaron un comportamiento estacional, con los mayores montos en los meses de primaveraverano. Sin embargo, las actividades enzimáticas no mostraron una clara variación estacional. Los mayores valores de mineralización y actividad enzimática en el bosque de $N$. obliqua, se deberían a la composición y características químicas de la hojarasca. Producto del cambio de uso de suelo y manejo silvícola, la plantación de $P$. radiata cambia la química y la relación $\mathrm{C} / \mathrm{N}$ del suelo con una menor tasa de descomposición de la materia orgánica, y como consecuencia, los procesos de mineralización $(\mathrm{C}, \mathrm{N})$, la actividad biológica y retorno de nutrientes al suelo se reducen en comparación con el bosque de $N$. obliqua.
\end{abstract}

Palabras clave: actividad biológica del suelo, bosques templados, plantaciones exóticas, suelos volcánicos.

\begin{abstract}
In Chile, commercial forests plantations have increased during the last decades due in part to replacement of native forests and conversion of agricultural soils. Pinus radiata D. Don has been the main tree planted, due to its rapid growth and adaptability. In the present study we proposed that biological activity varies along the year due to changes of precipitation, temperature and soil water content and mainly because the conversion of native forest to exotic $P$. radiata plantations alters the soil chemistry, $\mathrm{N}$ and $\mathrm{C}$ mineralization and the potential enzymatic activity in these soils. This hypothesis was examined in a Nothofagus obliqua (Mirb) Oerst forest and $P$. radiata plantation in central-southern Chile $\left(40^{\circ} 07^{\prime} \mathrm{S}, 72^{\circ} \mathrm{W}\right)$. In this study, the rate of nitrogen mineralization ( $\mathrm{N}$-min), carbon mineralization (C-min) and the potential enzymatic activity of soils (urease, protease and fluorecein diacetate hydrolysis) were determined between September 2003 and May 2005. Results showed that soil biological activity was significantly different between forest and plantations (Wilk's Lambda $=0.022 ; \mathrm{F}_{5,80}=733, \mathrm{P}<0,0001$ ), and among the months (Wilk's Lambda $=2.01 \mathrm{E}-6, \mathrm{~F}_{100,395}$ $=84, \mathrm{P}<0,0001)$, with values for $N$. obliqua forest significantly higher $($ Tukey $<0.01)$ than those for $P$. radiata plantation. $\mathrm{N}$-min and $\mathrm{C}$-min rates showed seasonal variability with the higher values in spring and summer months. For enzymatic activity there was not a clear seasonal variation. The higher values of $\mathrm{C}$ and
\end{abstract}


$\mathrm{N}$-min and enzymatic activity in the $N$. obliqua forest could be explained by differences in composition and chemistry of litter. Consequently, $P$. radiata plantation changed soil chemistry and $\mathrm{C} / \mathrm{N}$ ratio resulting in lower decomposition rates of organic matter and in consequence, reduced mineralization of $\mathrm{C}$ and $\mathrm{N}$ and soil biological activity compared to the original soil of $N$. obliqua forest.

Key words: soil biological activity, temperate forests, exotic plantations, volcanic-ash soil.

\section{INTRODUCCIÓN}

Los bosques templados de Chile y Argentina brindan un escenario único para estudiar los ciclos biogeoquímicos, ya que la química de las precipitaciones está exenta de contaminación industrial, por lo tanto, son principalmente procesos bióticos y abióticos no antropogénicos los regulan los ciclos internos y la exportación de nutrientes del ecosistema (Pérez et al. 2003). Estos bosques se caracterizan por la dominancia de nitrógeno orgánico disuelto tanto a nivel de entrada por vía atmosférica, como en las salidas, por vía agua de escorrentía (Hedin et al. 1995, Weathers et al. 2000, Perakis \& Hedin 2002). Estos patrones difieren marcadamente de las regiones industrializadas del mundo, como Europa y Norteamérica (Perakis et al. 2005, Bridget \& Emment 2002, Perakis \& Hedin 2002). De acuerdo a Hedin et al. (1995), los ecosistemas prístinos con bajos ingresos de nitrógeno $(\mathrm{N})$ constituyen un modelo de cómo funcionaban los bosques en épocas preindustriales y, por lo tanto, podrían ser un indicador sensible de incrementos en la depositación atmosférica de compuestos nitrogenados. El incremento de las actividades antropogénicas en el centro-sur de Chile, como la ganadería, agricultura intensiva y principalmente la conversión masiva del bosque nativo a plantaciones de especies forestales exóticas de rápido crecimiento, constituyen impactos que podrían alterar procesos claves que controlan los ciclos biogeoquímicos (Berg \& Matzner 1997, Godoy et al. 2001, 2005, Pérez et al. 2003). El cambio de uso del suelo afecta los niveles de carbono y nitrógeno en el suelo, principalmente a través de la pérdida y aceleración de los procesos de oxidación, que alteran la cantidad y composición de la materia orgánica del suelo (MOS) (Guo \& Gifford 2002). Estos cambios varían de acuerdo al clima, suelo, vegetación e intensidad de las prácticas de manejo (Lugo \& Brown 1993, Guo \& Gifford 2002).

Las plantaciones de Pinus radiata D. Don, en Chile, originalmente destinadas a suelos erosionados y de dunas, constituyen actualmente el cultivo más extensivo en el país con 1.600 .000 ha distribuidas principalmente entre $34^{\circ}$ y $40^{\circ} \mathrm{S}$ (Instituto Nacional Forestal, INFOR 2006). En Chile, la sustitución de bosques nativos por plantaciones de $P$. radiata ha sido un proceso importante, con consecuencias sociales, económicas y ambientales (Oyarzún et al. 2007). Frank \& Finckh (1997) evaluaron el impacto de las plantaciones de Pseudotsuga menziesii (Mirb) Franco sobre la vegetación y las propiedades del suelo en un Andisol de Chile, señalando para este último cambios significativos en la química, particularmente en el empobrecimiento de bases, cationes básicos y contenido de fósforo. Schalatter \& Otero (1995) y Buch \& Osorio (1987) señalan efectos negativos sobre el estado nutritivo del suelo producto de los monocultivos de $P$. radiata en el centro-sur de Chile, atribuido a las características químico-nutritivas de la hojarasca y disminución de la actividad biológica del suelo. Saviozzi et al. (2001), Aon et al. (2001) y Huygens et al. (2005) indicaron que cambios en el uso del suelo alteran significativamente la calidad y cantidad de la MOS, biomasa microbiana y sustrato potencialmente mineralizable. En este mismo contexto, Pérez et al. (2004) y Sicardi et al. (2004) señalaron diferencias en la dinámica de reciclaje de nutrientes entre bosques, destacando un mayor nivel de calcio y $\mathrm{N}$ respecto de una mayor cantidad de resina, grasas, lignina y abundancia de fenoles en suelos de latifoliadas y coníferas nativas, respectivamente. Cornelissen, (1996), Goh \& Heng (1987), Lambers et al. (1998) y Lusk et al. (2001) han señalado que las diferencias interespecíficas en las propiedades de la hojarasca inciden en los procesos locales de descomposición, mineralización de la MOS y disponibilidad de nutrientes, para la vegetación y microorganismos del suelo.

Las enzimas del suelo son consideradas 'sensores', ya que integran información sobre el estado y condiciones fisicoquímicas del 
suelo (Aon \& Colaneri 2001). Bacterias y hongos sintetizan y liberan enzimas extracelulares, tales como ureasas, proteasas, esterasas, fosfatasas, etc., catalizando las reacciones para la descomposición de la MOS y los ciclos de nutrientes en los ecosistemas terrestres (Taylor 1989, Zhang et al. 2005). La ureasa es una enzima que participa en el ciclo del $\mathrm{N}$, como catalizador de la reacción de hidrólisis de la urea en amonio y dióxido de carbono (Steubing et al. 2002). Las proteasas catalizan las reacciones que degradan proteínas y péptidos (Nannipieri et al. 1994), por lo que, al igual que ureasas, están involucradas en el ciclo del N. La hidrólisis de Fluorescein Diacetato (FDA) es una reacción que involucra diversos grupos de enzimas, tales como: proteasas, lipasas, esterasas, constituyendo un indicador sensible de la actividad microbiana total de la hojarasca y el suelo (Adam \& Duncan 2001, Green et al. 2006).

En el presente estudio se plantea que la actividad biológica del suelo en bosques y plantaciones varía temporalmente a través del año, asociada a variaciones estacionales en precipitación, temperatura y contenido de humedad de suelo, y que el cambio de cobertura de suelo desde un bosque templado de Nothofagus obliqua (Mirb) Oerst a una plantación con coníferas exóticas, modifica la química del suelo (calidad de la materia orgánica), y consecuentemente los procesos de mineralización de nitrógeno ( $\mathrm{N}-\mathrm{min})$, carbono (C-min) y la actividad enzimática potencial del suelo. Los objetivos de la presente investigación fueron: (a) Analizar y comparar $\mathrm{N}$-min, C-min y la actividad enzimática potencial del suelo en un bosque de $N$. obliqua y en una plantación de $P$. radiata en el centro sur de Chile; y (b) determinar la variación estacional de las actividades biológicas del suelo en respuesta a las variaciones de temperatura, precipitación y contenido de humedad del suelo.

\section{MATERIALES Y MÉTODOS}

\section{Área de estudio}

Está ubicada en el sector de Paillaco, provincia de Valdivia, $\left(40^{\circ} 07^{\prime} \mathrm{S}, 72^{\circ} 51^{\prime} \mathrm{O}\right)$ a $160 \mathrm{~m}$ de altura. El clima es templado lluvioso con influencia mediterránea, cuyas precipitaciones anuales fluctúan entre 1.390 y $2.940 \mathrm{~mm}$. La temperatura media anual es de 11,4 y $12,8{ }^{\circ} \mathrm{C}$; con temperatura medias mensuales de invierno entre 5,4 a $10,7{ }^{\circ} \mathrm{C}$ y en verano de 13,7 a 19,0 ${ }^{\circ} \mathrm{C}$ (Staelens et al. 2003). El suelo del área de estudio corresponde a Andisol (trumao) (Typic dystrandepts) (Tosso 1985).

Los sitios de estudio se encuentran distantes aproximadamente $1 \mathrm{~km}$ e incluyen un bosque de $N$. obliqua de aproximadamente 120 años y una plantación de $P$. radiata de 16 años. El suelo cubierto por $P$. radiata estuvo destinado previamente a la agricultura y originalmente correspondió a un bosque natural de $N$. obliqua. El bosque de $N$. obliqua presenta una estructura arbórea multiestratificada y diversa, con la participación caducifolias y siempreverdes (Cárcamo et al. 2004). El estrato dominante esta representado principalmente por $N$. obliqua, mientras que en el estrato codominante se presentan $N$. obliqua, Persea lingue Ness, Eucryphia cordifolia Cav, mientras que en el estrato inferior $P$. lingue, Gevuina avellana Mol., Aextoxicon punctatum R. et Pav., Laurelia sempervirens (R. et P.) Tul., E. cordifolia, Chusquea quila Kunth., Aristotelia chilensis (Mol) Stuntz y Raphithamnus spinosus (A.L. Juss.) Mol. La plantación de $P$. radiata es un monocultivo coetáneo cuyo estrato inferior está formado por A. chilensis, Ch. quila y Rubus contrictus Muell. et Lef. Características dasométricas más relevantes para cada parcela se presentan en la Tabla 1.

\section{TABLA 1}

Parámetros dasométricos (promedio) para el bosque de Nothofagus obliqua y la plantación de Pinus radiata centro-sur de Chile. Valores corresponden a tres réplicas por sitio

Dasometric parameters of Nothofagus obliqua forest and Pinus radiata plantation in south-central Chile. Values are means of three replicates per site

\begin{tabular}{lrr}
\hline Parámetro & N. obliqua & P. radiata \\
\hline DAP $(\mathrm{cm})$ & $42,5(10,5)$ & $28,5(4,3)$ \\
Altura $(\mathrm{m})$ & $32,0(7,5)$ & $24,0(4,9)$ \\
Área basal $\left(\mathrm{m}^{2} \mathrm{ha}^{-1}\right)$ & $55,0(11,7)$ & $48,0(6,8)$ \\
Densidad (árboles ha $\left.{ }^{-1}\right)$ & $757,0(44,7)$ & $1.500,0(24,6)$ \\
Cobertura de copa (\%) & $70,0(27,9)$ & $90,0(10,0)$
\end{tabular}


Variables microclimáticas y químicas del suelo

Para cada sitio se estableció una parcela permanente de $30 \times 30 \mathrm{~m}^{2}$. En cada parcela se registró continuamente, desde septiembre 2003 hasta mayo 2005, la temperatura del suelo. Adicionalmente, se instalo un pluviógrafo para el registro continuo de la precipitación, instalado en una pradera equidistante de ambas áreas experimentales. El contenido de humedad del suelo se determinó mensualmente en forma gravimétrica (Steubing et al. 2002). La capacidad hídrica máxima (CHM) para la caracterización del suelo se realizó según Steubing et al. (2002).

Para caracterizar químicamente el suelo de los sitios de estudio se recolectaron muestras compuestas (de 0-20 $\mathrm{cm}$ de profundidad). Se determinó $\mathrm{pH}$ en agua y en $\mathrm{KCl} 0,1 \mathrm{~N}$ (relación suelo: solución $1: 2,5)$, C total por oxidación con dicromato de potasio-ácido sulfúrico y determinación colorimétrica. Además, se determinó $\mathrm{N}$ total por el método de Kjeldahl, fósforo disponible (Olsen), fracción extraíble de $\mathrm{K}, \mathrm{Ca}, \mathrm{Mg}$ en extracto de acetato de amonio a $\mathrm{pH} 4,8$, y $\mathrm{Al}$ intercambiable (extracto de $\mathrm{KCl}$ $1 \mathrm{M})$. La suma de bases, como la cantidad de cationes metálicos intercambiables en solución de $\mathrm{HCl}$. Los análisis fueron realizados en el Laboratorio de Nutrición y Suelos Forestales, Universidad Austral de Chile.

Para realizar las mediciones de $\mathrm{N}$-min, $\mathrm{C}$-min y actividades potenciales enzimáticas, las muestras de suelo fueron tamizadas a $2 \mathrm{~mm}$. Todos los análisis se realizaron por triplicado, a partir de una muestra de suelo compuesta (originadas de la mezcla de cinco submuestras) de los primeros $10 \mathrm{~cm}$ de profundidad, obtenida de cinco subparcelas de $1 \mathrm{~m}^{2}$, ubicadas en forma aleatoria al interior de cada parcela. Todos los resultados del presente estudio son expresados en base suelo seco tamizado a $2 \mathrm{~mm}$.

\section{Mineralización del nitrógeno}

La incubación in situ se realizó en el interior de cilindros de policloruro de vinilo (PVC) con tapa para evitar la lixiviación del $\mathrm{NO}_{3}$. El tiempo de incubación en cada parcela fue de 30 días (Raison et al. 1987, Steubing et al. 2002). Para cada período, en el tiempo cero y a los 30 días se cuantificó el monto de $\mathrm{N}$ en forma de amonio $\left(\mathrm{N}-\mathrm{NH}_{4}{ }^{+}\right)$y nitrato $\left(\mathrm{N}-\mathrm{NO}_{3}{ }^{-}\right)$, a través de la óxido-reducción y destilación por arrastre de vapor de extractos en $\mathrm{KCl}(2 \mathrm{M})$ del suelo $(2: 1)$ y titulación ácida con $\mathrm{HCl}(0,01 \mathrm{~N})$ (Bremner 1965). Siendo la suma de ambas formas de $\mathrm{N}$ inorgánico, la $\mathrm{N}$-min. Los valores se expresan en mg $\mathrm{N}$ g suelo ${ }^{-1} \mathrm{~d}^{-1}$.

\section{Mineralización del carbono}

Se determinó mediante la respiración potencial del suelo con solución alcalina de $\mathrm{Ba}(\mathrm{OH})_{2}$, según el método Isermeyer descrito por Alef (1995). Los resultados se expresan en $\mathrm{mg}$ de $\mathrm{CO}_{2} 100 \mathrm{~g}$ suelo ${ }^{-1} \mathrm{~h}^{-1}$. Para comparar los resultados de $\mathrm{C}$-min en ambos sitios, los valores de $\mathrm{CO}_{2}$ fueron estandarizados en función de la cantidad de carbono total de cada parcela.

\section{Actividades enzimáticas potenciales}

La actividad de ureasa se determinó según el método descrito por Steubing et al. (2002), los valores se expresan en mg N-NH${ }_{4}^{+}$g suelo ${ }^{-1} \mathrm{~h}^{-1}$. La actividad proteasa por el método descrito por Ladd \& Butler (1972), cuyos valores se expresan en mg de tirosina $g$ suelo ${ }^{-1} 2 \mathrm{~h}^{-1}$. La hidrólisis del FDA (Fluorescein Diacetato) se realizó mediante la metodología de Schnürer \& Rosswall (1982), modificada por Adam \& Duncan (2001), y los valores se expresaron en $\mu \mathrm{g}$ fluoresceína g suelo ${ }^{-1} \mathrm{~h}^{-1}$.

\section{Análisis estadístico}

Se usó análisis de varianza multivariado (MANOVA) de dos vías para evaluar los efectos de los factores tipo de vegetación ( $\mathrm{n}=$ 2) y periodo de medición (mes, $n=22$ ), sobre las variables dependientes $\mathrm{N}$-min, C-min y actividades enzimáticas potenciales (ureasa, proteasa e hidrólisis del FDA). Antes de realizar el análisis estadístico se evaluaron los supuestos de normalidad (prueba de Lilliefors) y homocedasticidad de varianza (prueba de Levene) (Zar 1996) y se realizaron transformaciones logarítmicas cuando estos supuestos no se cumplieron. Para la comparación de medias se utilizó la prueba a posteriori de Tukey $(\mathrm{P}<0,05)$ (Zar 1996). Se usó análisis de correlación simple para estimar el grado de asociación entre las variables dependientes ( $\mathrm{N}$-min, $\mathrm{C}$-min y actividades potenciales enzimáticas) y microclimáticas (contenido de humedad del suelo, temperatura 
y precipitación) para cada sitio de estudio. Los análisis estadísticos fueron realizados usando el programa STATISTICA versión 6.0.

\section{RESULTADOS}

\section{Variables microclimáticas y química del suelo}

Durante el periodo de medición (septiembre 2003-septiembre 2004) la precipitación fue $2.225 \mathrm{~mm}$ en el área de estudio. Las temperaturas medias mensuales del suelo fluctuaron entre 7,6 a $16,7^{\circ} \mathrm{C}$ para el bosque de $N$. obliqua y entre 8,5 a $21,6{ }^{\circ} \mathrm{C}$ para la plantación de $P$. radiata. En ambas parcelas de estudio la máxima temperatura se registró en febrero 2005. Sin embargo, el valor promedio fue mayor en $P$. radiata $\left(21,7^{\circ} \mathrm{C}\right)$ que en $N$. obliqua $\left(15,8{ }^{\circ} \mathrm{C}\right)$. En cambio, la temperatura mínima fue registrada en septiembre 2003 en $P$. radiata $\left(6,5^{\circ} \mathrm{C}\right)$ y septiembre 2004 en bosque de $N$. obliqua $\left(10,0{ }^{\circ} \mathrm{C}\right)$. Los rangos de temperatura entre máxima y mínima fueron mayores en la plantación que en el bosque (Fig. 1A y 1B).

La capacidad hídrica máxima (CHM) del suelo del bosque de $N$. obliqua fue $140 \%$ y en la plantación de $P$. radiata de un $90 \%$. El contenido de humedad del suelo en base CHM para el bosque $N$. obliqua varió desde un 16 a un $45 \%$ y para la plantación $P$. radiata, entre un 16 a un $44 \%$ (Fig. 1B).

Las características químicas del suelo del bosque de $N$. obliqua fueron favorables para el desarrollo de la comunidad vegetal (Tabla 2), principalmente en relación $\mathrm{pH}$ en $\mathrm{KCl}, \mathrm{C}$ total, $\mathrm{N}$ total, relación $\mathrm{C} / \mathrm{N}$, disponibilidad de $\mathrm{Ca}, \mathrm{y}$ suma de bases. En ambas parcelas el fósforo disponible fue bajo, en consideración a estándares nutricionales (Will 1985). La saturación de aluminio fue muy diferente entre los sitios, con valores de 0,21 y $1,45 \%$ para $N$. obliqua y $P$. radiata, respectivamente.

MANOVA de dos vías indicó que el factor tipo de bosque (Lambda de Wilk $=0,022 ; \mathrm{F}_{5}, 80$ $=733 ; \mathrm{P}<0,0001)$, y período de medición $\left(\right.$ Lambda de Wilk $=1,01 \mathrm{E}-6 ; \mathrm{F}_{100,394}=84 ; \mathrm{P}<$ $0,0001)$ incidieron significativamente en las variables $\mathrm{N}$-min, C-min y actividad enzimática potencial (ureasa, proteasa e hidrólisis del FDA) Tabla 3. El análisis no mostró interacción significativa entre estos factores $(\mathrm{P}>0,05)$.

\section{TABLA 2}

Características químicas del suelo $(0-20 \mathrm{~cm})$ en el bosque de Nothofagus obliqua y la plantación de Pinus radiata, centro-sur de Chile

Chemical characteristics of soils (0-20 cm) in Nothofagus obliqua forest and Pinus radiata plantation, south-central Chile

\begin{tabular}{lrr}
\hline Variable & N. obliqua & P. radiata \\
\hline $\mathrm{pH} \mathrm{H} \mathrm{H}_{2} \mathrm{O}$ & 6,00 & 5,50 \\
$\mathrm{pH} \mathrm{KCl}$ & 5,30 & 4,50 \\
$\mathrm{C}$ total (\%) & $* 14,00$ & $* 9,40$ \\
$\mathrm{C}$ total (\%) & 11,20 & 5,07 \\
$\mathrm{~N}$ total (\%) & 0,82 & 0,26 \\
$\mathrm{C} / \mathrm{N}$ & 13,70 & 19,70 \\
$\mathrm{P}$ disponible Olsen $\left(\mathrm{mg} \cdot \mathrm{kg}^{-1}\right)$ & 3,20 & 3,20 \\
$\mathrm{~K}$ extraíble $\left(\mathrm{mg} \cdot \mathrm{kg}^{-1}\right)$ & 142,00 & 185,00 \\
Ca extraíble $\left(\mathrm{mg} \cdot \mathrm{kg}^{-1}\right)$ & $3.290,00$ & 966,00 \\
Mg extraíble $\left(\mathrm{mg} \cdot \mathrm{kg}^{-1}\right)$ & 462,00 & 208,00 \\
Sumas bases $\left(\mathrm{cmol}+\mathrm{kg}^{-1}\right)$ & 21,00 & 7,21 \\
Saturación Al $(\%)$ & 0,21 & 1,45 \\
\hline
\end{tabular}

* Corresponde al contenido de C total (\%) para los primeros $10 \mathrm{~cm}$ de profundidad.

Análisis multivariado (MANOVA) de dos vías, para los factores fijos: tipo de bosque y periodo de medición, y su interacción, para todas las variables en estudio (N-min, C- min y actividad enzimática (ureasa, proteasa e hidrólisis del FDA)

Two-way MANOVA for the factors: forest type and period of time and their interaction, for all the variables in study (N-min, C-min and enzyme potential activities (urease, protease and the microbial activity (FDA))

\begin{tabular}{lccccc}
\hline Fuente de variación & Lambda de Wilk & Valor de Fisher & $\begin{array}{c}\text { Grados de } \\
\text { libertad }\end{array}$ & $\begin{array}{c}\text { Grados de libertad } \\
\text { del error }\end{array}$ & Valor de P \\
\hline Tipo de bosque & 0,022 & 733 & 5 & 80 & $<0,001^{* * *}$ \\
Periodo de medición & $1,01 \mathrm{E}-6$ & 84 & 100 & 395 & $<0,001^{* * *}$ \\
Bosque x periodo de medición & $24,2 \mathrm{E}-3$ & 6,50 & 100 & 395 & $=0,0754$ \\
\hline
\end{tabular}




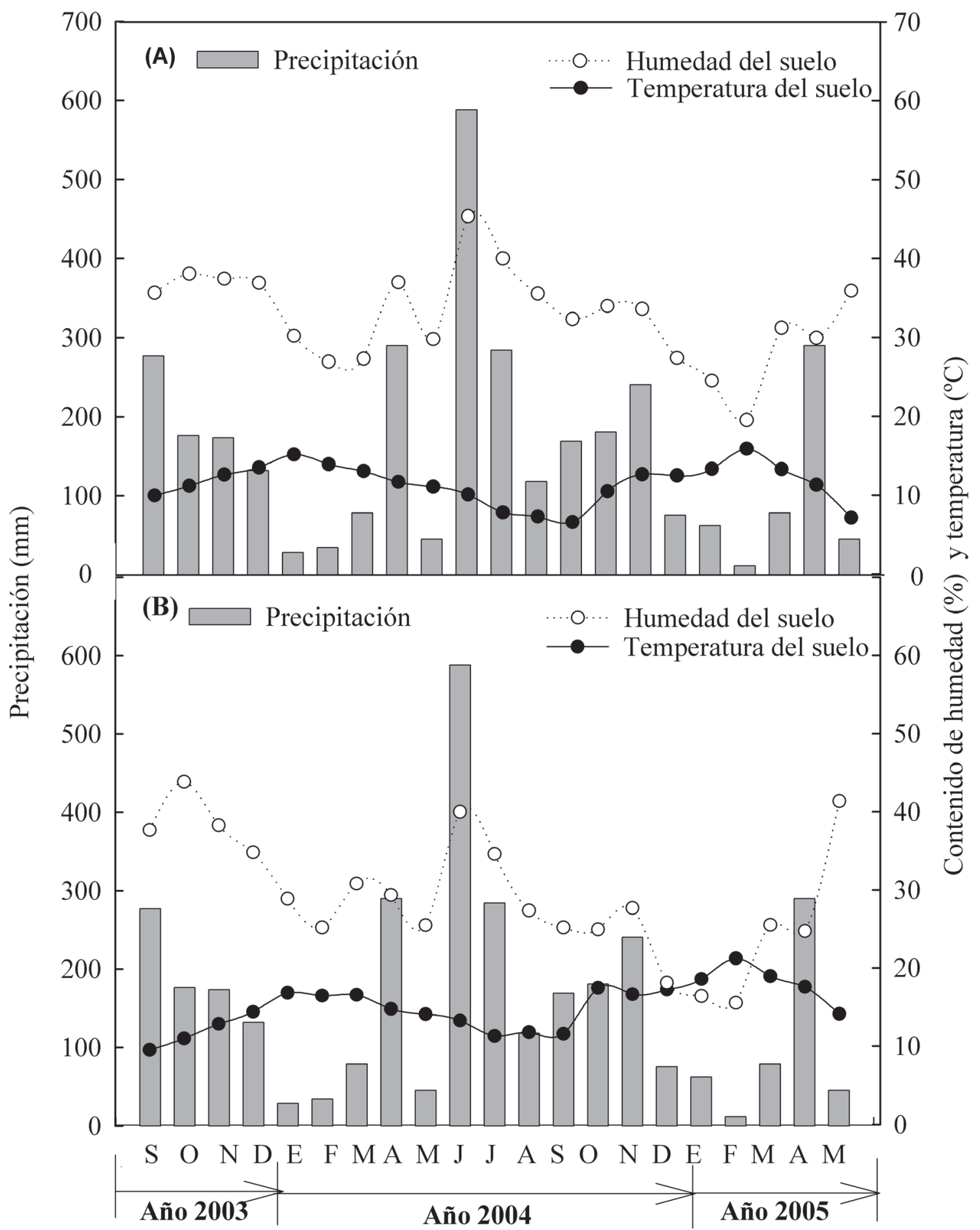

Fig. 1: Precipitación mensual (mm) y contenido de humedad del suelo (\%) en el bosque de Nothofagus obliqua (A) y la plantación de Pinus radiata (B) desde septiembre 2003 hasta mayo 2005.

Monthly precipitation ( $\mathrm{mm}$ ) and soil moisture (\%) in Nothofagus obliqua forest (A) and Pinus radiata plantation (B) between September 2003 and May 2005. 
En este estudio, las tasas de amonificación neta en el suelo del bosque de $N$. obliqua variaron entre $-1,95$ a $4,38 \mathrm{mg}$ de $\mathrm{N}_{-} \mathrm{NH}_{4} \mathrm{~g}$ suelo ${ }^{-1} \mathrm{~d}^{-1}$. En comparación, en la plantación de $P$. radiata los valores de amonificación neta fluctuaron entre $-2,43$ a $2,60 \mathrm{mg}$ de $\mathrm{N}-\mathrm{NH}_{4} \mathrm{~g}$ suelo ${ }^{-1} \mathrm{~d}^{-1}$ (Fig. 2).

En relación a la nitrificación neta $\left(\mathrm{N}-\mathrm{NO}_{3}\right)$, los valores en el bosque de $N$. obliqua variaron estacionalmente entre $-2,6$ a $3,75 \mathrm{mg}$ de $\mathrm{N}_{-} \mathrm{NO}_{3}$ g suelo ${ }^{-1} \mathrm{~d}^{-1}$. En la plantación, los valores fueron más bajos en promedio y variaron entre $-4,12$ a $3,65 \mathrm{mg}$ de $\mathrm{N}-\mathrm{NO}_{3} \mathrm{~g}$ suelo $^{-1} \mathrm{~d}^{-1}$ (Fig. 3)

En cuanto a la mineralización neta (N-min), en el bosque de $N$. obliqua los valores fluctuaron entre $-3,47$ a 7,98 mg N g suelo ${ }^{-1} \mathrm{~d}^{-1}$ $\mathrm{y}$ fueron superiores en promedio a los registrados en la plantación de $P$. radiata, donde N-min varió entre $-4,12$ a 3,65 mg N g suelo ${ }^{-1} \mathrm{~d}^{-1}$ (Fig. 4).
En el bosque de $N$. obliqua N-min no mostró correlación significativa con las variables dependientes en estudio ni con las variables microclimáticas. En la plantación de $P$. radiata $\mathrm{N}$-min solo mostró correlación significativa con la actividad enzimática potencial ureasa $(\mathrm{r}=0,54 ; \mathrm{P}<0,05)$.

\section{Mineralización del carbono}

En condiciones de laboratorio, las tasas de liberación de $\mathrm{CO}_{2}$ del suelo del bosque de $N$. obliqua fluctuaron entre 0,94 y 4,26 mg de $\mathrm{CO}_{2}$ $100 \mathrm{~g} \mathrm{suelo}^{-1} \mathrm{~h}^{-1}$. En lo que respecta a la plantación de $P$. radiata, las tasas de liberación de $\mathrm{CO}_{2}$ fluctuaron entre 0,55 a $3,70 \mathrm{mg}$ de $\mathrm{CO}_{2}$ 100 g suelo $^{-1} \mathrm{~h}^{-1}$ (Fig. 5). Los valores de ambas parcelas presentaron una significativa correlación con el contenido de humedad del suelo $(\mathrm{r}=0,60$ para $N$. obliqua y $\mathrm{r}=0,44$ para $P$. radiata).

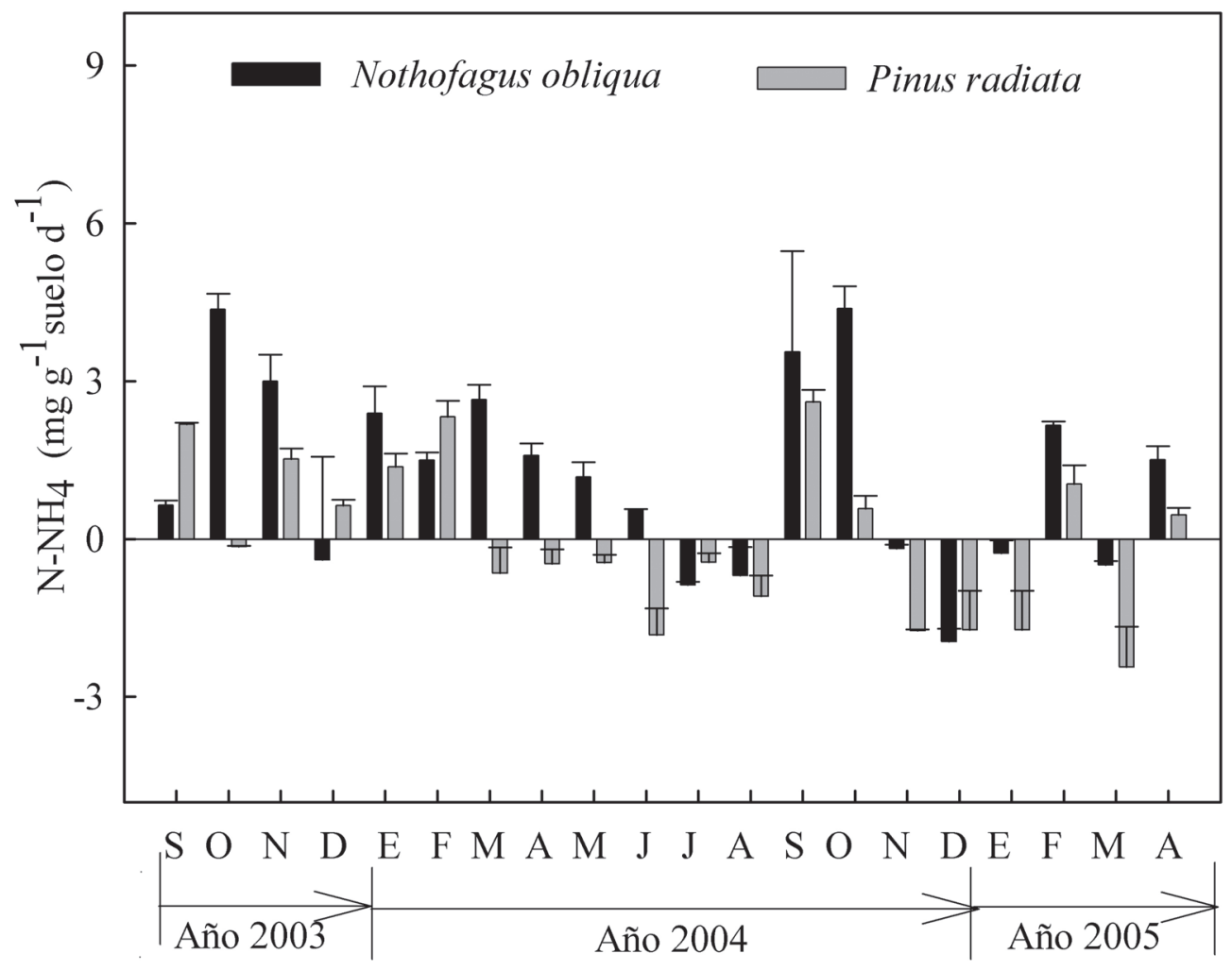

Fig. 2: Variación mensual de las tasas de amonificación neta (mg $\mathrm{N}$ g suelo $\left.{ }^{-1} \mathrm{~d}^{-1}\right)$, de muestras de suelo incubadas in situ en el bosque de Nothofagus obliqua y la plantación de Pinus radiata, desde septiembre 2003 a abril 2005. Barras representan la desviación estándar $(\mathrm{n}=3)$.

Monthly variation of net amonification ( $\mathrm{mg} \mathrm{N} \mathrm{g} \mathrm{suelo}{ }^{-1} \mathrm{~d}^{-1}$ ), in soil samples incubated in situ in Nothofagus obliqua forest and Pinus radiata plantation, between September 2003 and May 2005. Bars represent the standard deviation of the mean $(n=3)$. 


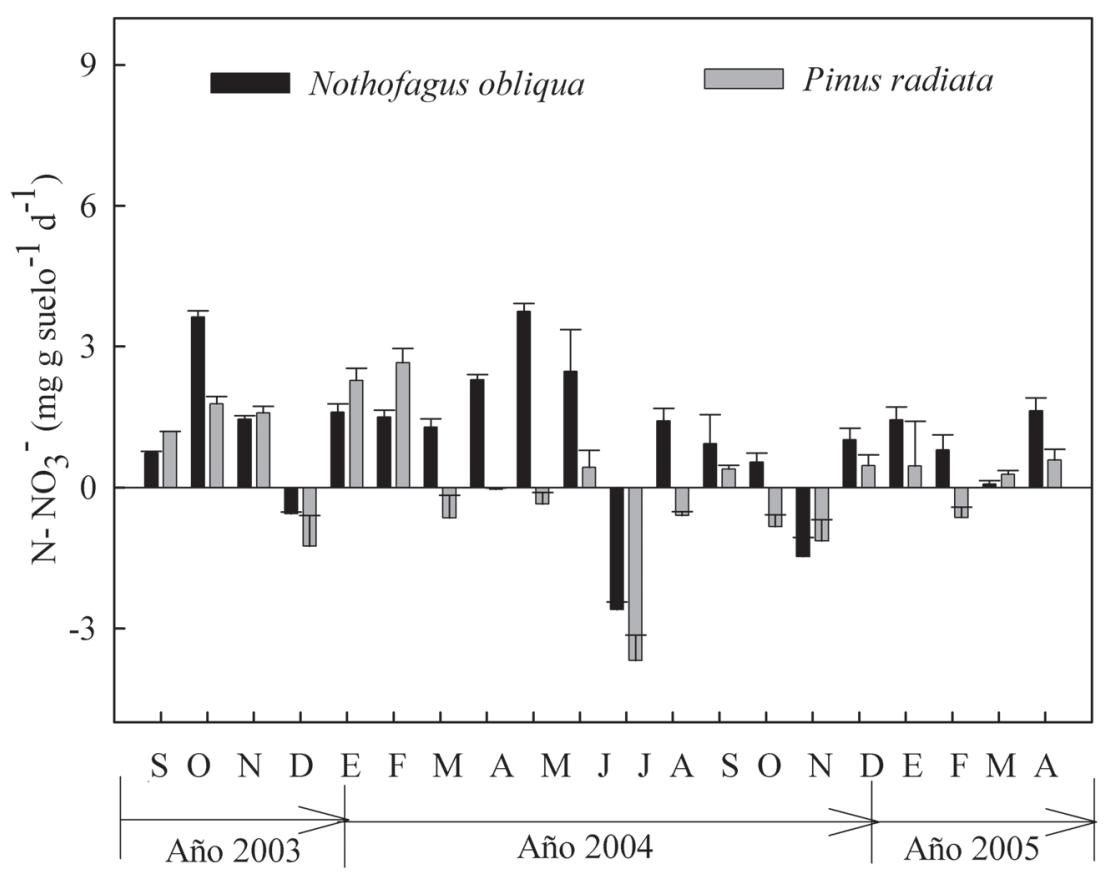

Fig. 3: Variación mensual de las tasas de nitrificación $\left(\mathrm{mg} \mathrm{N} g\right.$ suelo $\left.{ }^{-1} \mathrm{~d}^{-1}\right)$ de muestras de suelo incubadas in situ en el bosque de Nothofagus obliqua y de la plantación de Pinus radiata, desde septiembre 2003 a abril 2005. Barras representan la desviación estándar $(\mathrm{n}=3)$.

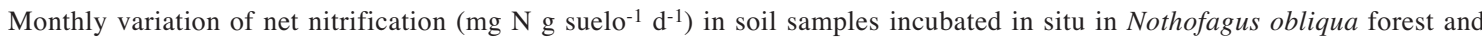
Pinus radiata plantation, between September 2003 and May 2005. Bars represent the standard deviation of the mean $(\mathrm{n}=3)$.

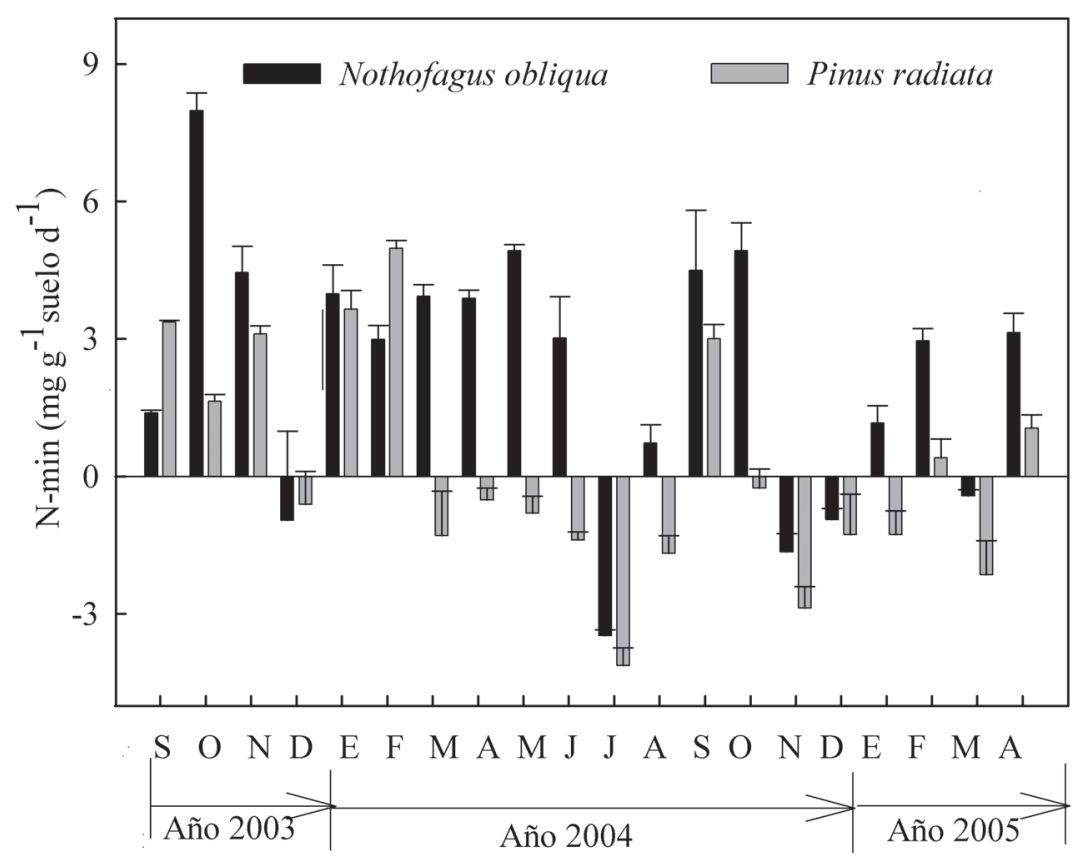

Fig. 4: Variación mensual de las tasas de mineralización neta ( $\mathrm{mg} \mathrm{N}$ g suelo $\left.{ }^{-1} \mathrm{~d}^{-1}\right)$ de muestras de suelo incubadas in situ en el bosque de Nothofagus obliqua y en la plantación de Pinus radiata, desde septiembre 2003 a abril 2005. Barras representan la desviación estándar $(n=3)$.

Monthly variation of net mineralization $\left(\mathrm{mg} \mathrm{N}\right.$ g suelo $\left.{ }^{-1} \mathrm{~d}^{-1}\right)$ in soil samples incubated in situ in Nothofagus obliqua forest and Pinus radiata plantation, between September 2003 and May 2005. Bars represent the standard deviation $(n=3)$. 


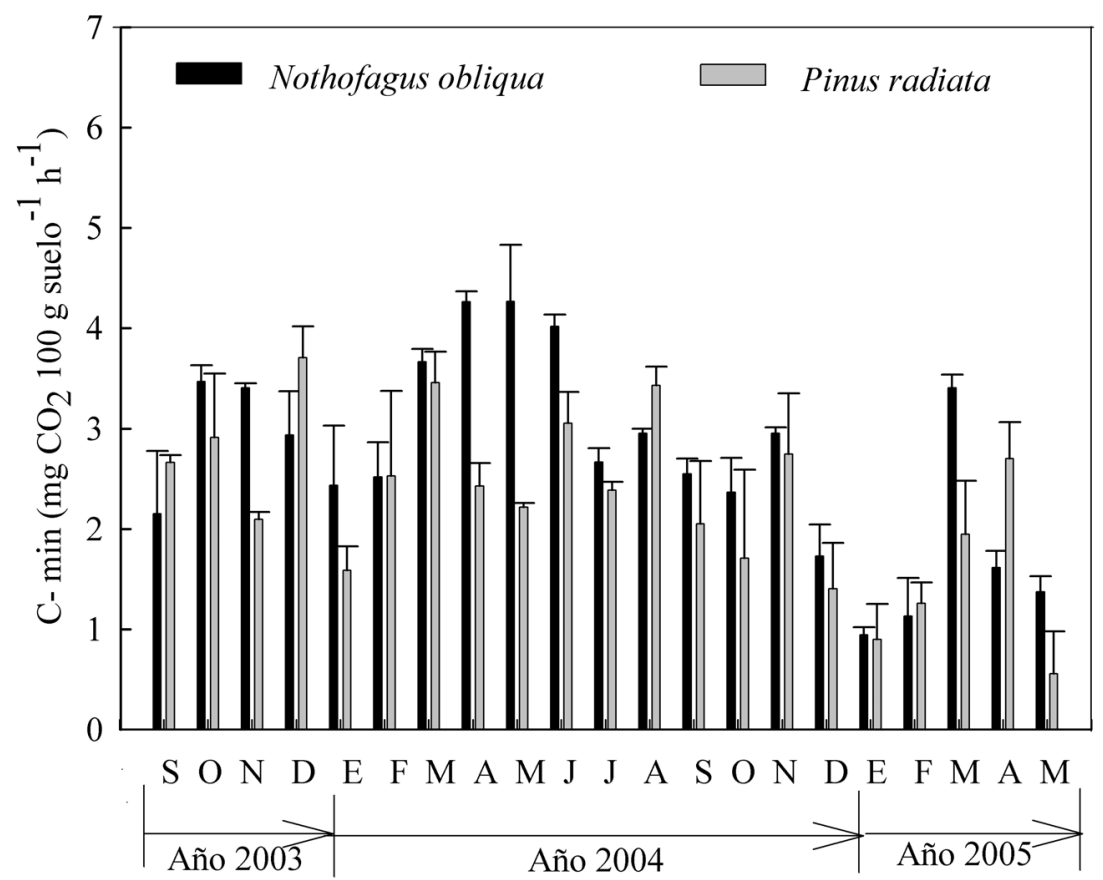

Fig. 5: Variación mensual de la respiración potencial del suelo $\left(\mathrm{mg}\right.$ de $\left.\mathrm{CO}_{2} 100 \mathrm{~g} \mathrm{suelo}^{-1} \mathrm{~h}^{-1}\right)$ en el bosque de Nothofagus obliqua y la plantación de Pinus radiata, desde septiembre 2003 a mayo 2005, barras representan la desviación estándar $(n=3)$.

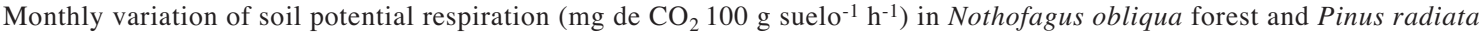
plantation, between September 2003 and May 2005, bars represent the standard deviation $(\mathrm{n}=3)$.

\section{Actividades enzimáticas potenciales}

Los valores de actividad potencial de ureasa en el suelo del bosque de $N$. obliqua variaron

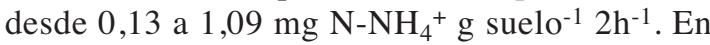
la plantación $P$. radiata los valores variaron desde 0,07 a $0,44 \mathrm{mg} \mathrm{N}-\mathrm{NH}_{4}{ }^{+} \mathrm{g}$ suelo ${ }^{-1} 2 \mathrm{~h}^{-1}$ (Fig. 6). Los valores de actividad en suelo de $N$. obliqua fueron superiores a los de la plantación, con excepciones en los meses de abril 2003, agosto 2004 y enero-febrero 2005. Esta variable no mostró correlación significativa con las variables microclimáticas ni con las variables dependientes estudiadas. De este modo la actividad de ureasa en ambos ecosistemas fue variable estacionalmente, con los menores valores en los meses de verano, donde la temperatura fue mayor y el contenido de humedad del suelo menor (Fig. 6).

Los valores de actividad de proteasa en el suelo del bosque de $N$. obliqua variaron desde 1,52 a 7,27 mg tirosina g suelo ${ }^{-1} 2 \mathrm{~h}^{-1}$, mientras que en la plantación de $P$. radiata los valores de actividad se registraron desde 0,56 a 5,88 mg tirosina g suelo ${ }^{-1} 2 \mathrm{~h}^{-1}$ (Fig. 7).
Los valores del bosque de $N$. obliqua fueron significativamente superiores a los valores de $P$. radiata, con algunas excepciones en los meses de mayo 2003, octubre-noviembre 2004 y enero-febrero 2005. Proteasa no mostró correlación significativa con las variables microclimáticas, pero sí con la actividad potencial del FDA. Así, la actividad potencial proteasa fue variable durante todo el período de medición. Mientras que ureasa presentó una tendencia estacional, con los mayores montos en el período marzo-junio 2004.

La actividad del FDA varió desde 2,50 a 21,30 $\mu \mathrm{g}$ fluoresceína g suelo ${ }^{-1} \mathrm{~h}^{-1}$ en el bosque de Nothofagus, mientras que en la plantación de $P$. radiata variaron desde 1,70 a 13,27 $\mu \mathrm{g}$ fluoresceína $g$ suelo ${ }^{-1} \mathrm{~h}^{-1}$. Los valores para la actividad potencial del FDA en bosque de $N$. obliqua fueron generalmente superiores a los de $P$. radiata (Fig. 8), con excepciones en los meses de febrero, junio y agosto 2004 y febrero 2005. La actividad FDA se correlacionó positivamente entre las dos áreas de estudio $(\mathrm{r}$ $=0,80 ; \mathrm{P}<0,05)$, pero no con las variaciones microclimáticas. Sin embargo, en el bosque de 


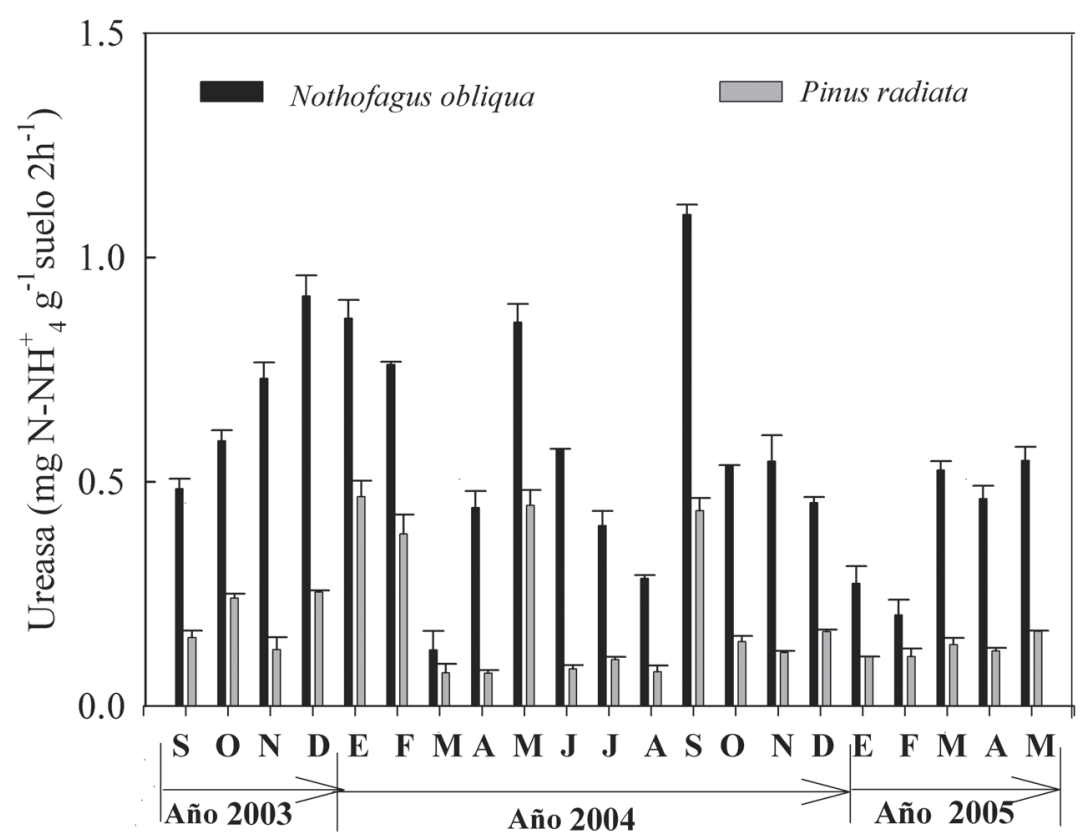

Fig. 6: Variación mensual en la actividad potencial ureasa $\left(\mathrm{mg} \mathrm{N}-\mathrm{NH}_{4}{ }^{+}\right.$g suelo $\left.{ }^{-1} 2 \mathrm{~h}^{-1}\right)$ en el suelo del bosque de Nothofagus obliqua y la plantación de Pinus radiata, desde septiembre 2003 a mayo 2005, barras representan la desviación estándar $(\mathrm{n}=3)$.

Monthly variation of urease potential activity $\left(\mathrm{mg} \mathrm{N}-\mathrm{NH}_{4}{ }^{+} \mathrm{g} \mathrm{suelo}^{-1} 2 \mathrm{~h}^{-1}\right)$ in soils of Nothofagus obliqua forest and Pinus radiata plantation, between September 2003 and May 2005, bars represent the standard deviation $(\mathrm{n}=3)$.

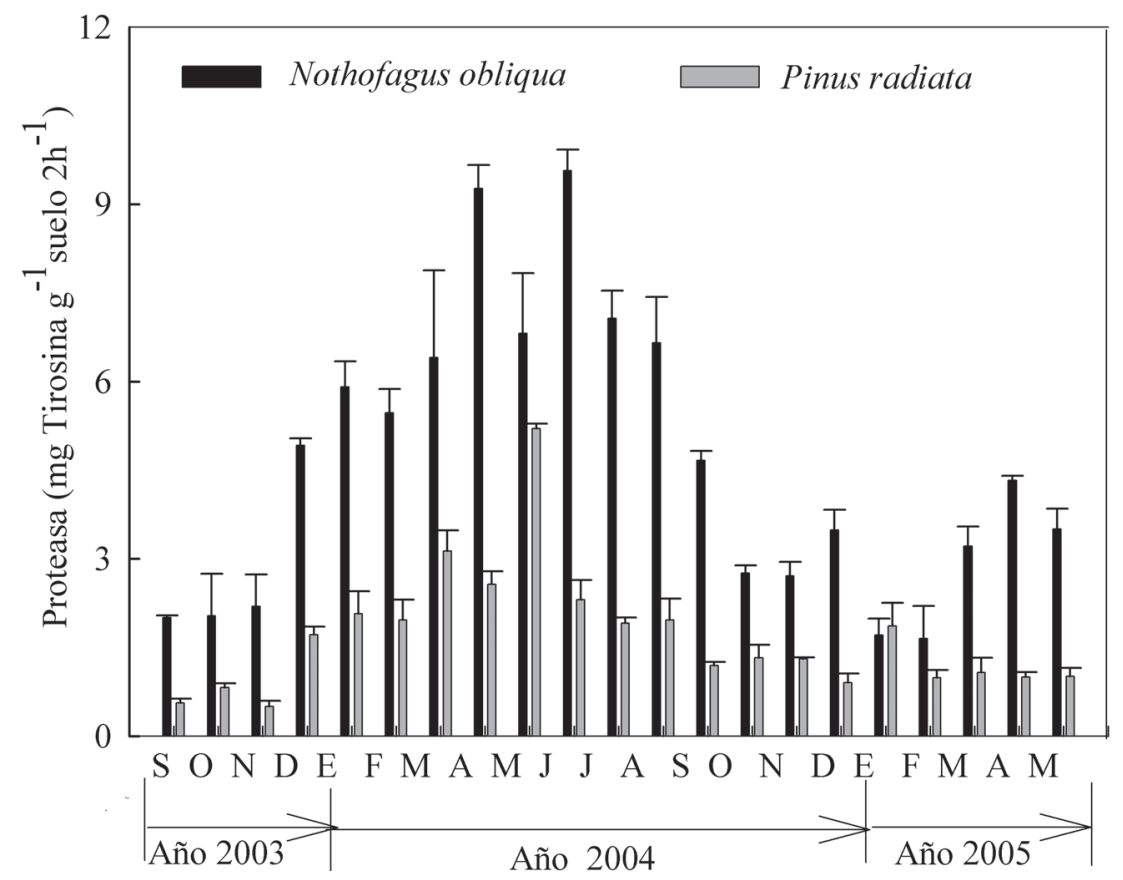

Fig. 7: Variación mensual de la actividad potencial proteasa ( $\mathrm{mg}$ de Tirosina $\mathrm{g}$ suelo $\left.^{-1} 2 \mathrm{~h}^{-1}\right)$ en suelos del bosque de Nothofagus obliqua y la plantación de Pinus radiata, desde septiembre 2003 a mayo 2005, barras representan la desviación estándar $(n=3)$.

Monthly variation of the protease potential activity (mg de tirosina g suelo-1 $2 \mathrm{~h}^{-1}$ ) in soils of Nothofagus obliqua forest and Pinus radiata plantation, between September 2003 and May 2005, bars represent the standard deviation $(\mathrm{n}=3)$. 
$N$. obliqua FDA se correlacionó positiva y significativamente con $\mathrm{C}$-min $(\mathrm{r}=0,43 ; \mathrm{P}<$ $0,05)$ y con proteasa $(\mathrm{r}=0,47 ; \mathrm{P}<0,05)$. En el suelo de la plantación de $P$. radiata, FDA solo mostró correlación positiva y significativa con la actividad potencial proteasa $(\mathrm{r}=0,70 ; \mathrm{P}<$ $0,05)$. Respecto de la FDA, en el período de estudio no se observó una tendencia estacional.

\section{DISCUSIÓN}

Una evaluación de la diversidad microbiológica en suelos no solo debe estar basada en la cuantificacion e identificación de los microorganismos involucrados, sino que es esencial investigar su papel funcional. El estudio de los procesos de descomposición, mineralización de la materia orgánica y las capacidades enzimáticas de la biota del suelo es una forma de analizar sus actividades y proporciona información cualitativa respecto a los procesos de transformación de $\mathrm{N}$ y $\mathrm{C}$ y los ciclos biogeoquímicos (Valenzuela et al. 2001). El microclima de la región determina las características de la vegetación e influye en el metabolismo diario, estacional y anual de la biota en el ecosistema. Por otro lado, cobertura y estructura de la vegetación tienen influencia sobre los diversos factores microclimáticos (humedad del aire, viento, radiación y temperatura) que determinan finalmente el balance energético e hídrico de las plantas y la biota en general, incluyendo los microorganismos del suelo (Steubing et al. 2002).

En el área de estudio, la mayor amplitud térmica, basada en las extremas máximas y mínimas, se registró en la plantación de $P$. radiata, posiblemente con consecuencias negativas para la actividad biológica del suelo. La menor temperatura promedio a nivel del suelo del bosque de $N$. obliqua en primaveraverano podría ser producto de mayor estratificación del dosel y cobertura del estrato herbáceo (Donoso 1993), en comparación a la plantación de $P$. radiata. La menor CHM del suelo en la plantación de $P$. radiata en comparación a $N$. obliqua se relaciona con el bajo nivel de MOS, expresado en los contenidos de $\mathrm{C}$ y $\mathrm{N}$ del suelo superficial. Una

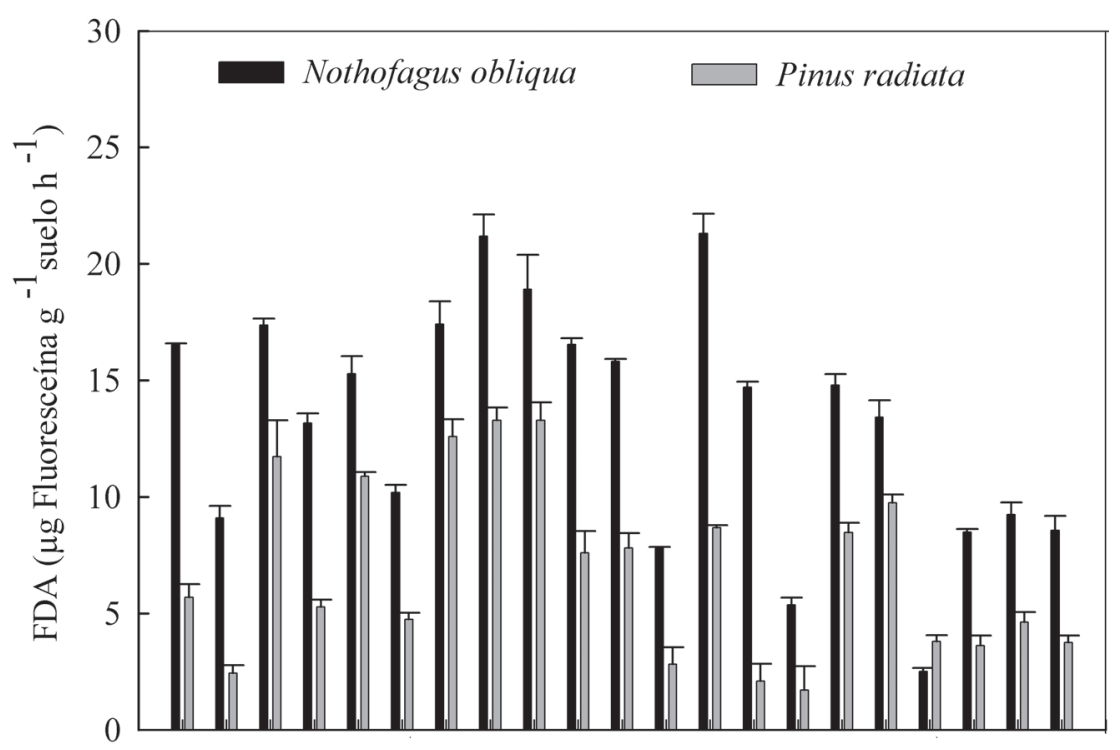

\begin{tabular}{|c|c|c|}
\hline Año $200 \widehat{3}$ & Año 2004 & Año $2005^{-}$ \\
\hline
\end{tabular}

Fig. 8: Hidrólisis del FDA ( $\mu$ g Fluoresceína g suelo ${ }^{-1} \mathrm{~h}^{-1}$ ) en el bosque de Nothofagus obliqua y la plantación de Pinus radiata, desde septiembre 2003 a mayo 2005, barras representan la desviación estándar $(\mathrm{n}=3)$.

Monthly variation of the FDA hydrolytic ( $\mu \mathrm{g}$ fluoresceína $\mathrm{g}$ suelo ${ }^{-1} \mathrm{~h}^{-1}$ ) in soils of Nothofagus obliqua forest and Pinus radiata plantation, between September 2003 and May 2005, bars represent the standard deviation $(n=3)$. 
mayor evapotranspiración es consecuencia directa de las plantaciones forestales con una consecuente disminución de la disponibilidad de agua en el suelo, acoplada con la compactación del suelo, producto del uso agrícola y forestal (Oyarzún et al. 2007).

Suelos del centro-sur de Chile originados de cenizas volcánicas, poseen un estatus de nutrientes y minerales que favorecen el desarrollo del bosque de $N$. obliqua. Por el contrario, frente al cambio de uso de suelo y establecimiento de monocultivo de coníferas exóticas, se produciría un crecimiento más acelerado de los árboles asociado a una mayor demanda de nutrientes, resultando en empobrecimiento del sustrato y posterior carencia de elementos para las plantas y biota del suelo. El impacto del cambio de uso del suelo es más significativo después de rotaciones sucesivas de plantaciones en la región (Buch \& Osorio 1987). En el presente estudio se comprobaron diferencias importantes en los valores de $\mathrm{pH}$, nutrientes y minerales, como asimismo las bases intercambiables y aluminio, con una disminución del estatus nutritivo del suelo de $P$. radiata en comparación al bosque nativo. Una situación similar han observado Schlatter \& Otero (1995) en el suelo mineral superficial de $P$. radiata, atribuido a las características químico-nutritivas de la hojarasca, pobre en calcio y nitrógeno. Además, el aporte de MOS de $P$. radiata, con alta relación $\mathrm{C} / \mathrm{N}$ y presencia de compuestos inhibidores de actividad biológica del suelo (e.g., resina, ceras) producen una menor tasa de retorno de nutrientes y de descomposición de hojarasca, comparada con bosques templados (Schlatter \& Otero 1995, Lusk et al. 2001). En ambas parcelas la disponibilidad de fósforo fue baja y característica de suelos de origen volcánico en Chile (Borie \& Zunino 1983) y no se registró influencia del cambio de uso de suelo. Cationes y suma de bases en general fueron notoriamente reducidas en el suelo de $P$. radiata, como fue documentado por Schlatter \& Otero (1995). La mayor disponibilidad de aluminio es una consecuencia directa del $\mathrm{pH}$ más ácido en $P$. radiata. Según Donoso (1993), un $\mathrm{pH}$ menor a 7,0 produce dificultades en la absorción de $\mathrm{Ca}$ y $\mathrm{Mg}$, y por lo tanto las principales bases son reemplazadas por $\mathrm{H}^{+}$, intensificando lavado de bases y movilización de aluminio. Por otro lado, altas concentraciones de
$\mathrm{H}^{+}$producen cambios en la abundancia y actividad de organismos del suelo, donde bacterias y lombrices disminuyen su actividad y adquieren una mayor connotación los hongos, asociado a una baja diversidad específica (Buch \& Osorio 1987). Este aspecto crítico con empobrecimiento cuali-cuantitativo de fauna del suelo de $P$. radiata al comparar con bosque templado de la región, ha sido notado por Buch \& Osorio (1987) y Schlatter \& Otero (1995).

Aun cuando las tasas de N-min no mostraron correlación con las variables microclimáticas en ambos sitios de estudio, los mayores valores del bosque de $N$. obliqua estuvieron asociados a mayores temperaturas y humedad del suelo. Para $P$. radiata las tasas de mineralización durante los meses de otoño e invierno fueron en su mayoría negativas o muy bajas. Tasas de $\mathrm{N}$-min positivas indican que el $\mathrm{N}$ está potencialmente disponible para el consumo de las plantas y microorganismos del suelo. Estos resultados concuerdan en parte con ensayos realizados por Pérez et al. $(1998,2004)$ en bosques nativos de coníferas y latifoliadas del sur de Chile, quienes, a diferencia de nuestros resultados, reportan una acentuada estacionalidad en la tasas de $\mathrm{N}$-min y una correlación positiva y significativa con la precipitación mensual. La alta correlación en las tasas de mineralización en los bosques de Chiloé podría estar dada por las mayores precipitaciones registradas en los bosques montanos de Chiloé $(\sim 5.500 \mathrm{~mm})$ en comparación con sitios de la Depresión Intermedia $(\sim 2.225 \mathrm{~mm})$.

Valores negativos de las tasas de mineralización, indican inmovilización biótica y abiótica neta de N-min (Piirainen et al. 2002, Pérez et al. 2003). La plantación de $P$. radiata presentó una mayor tasa de inmovilización que el bosque de $N$. obliqua, principalmente en los meses de otoño. La inmovilización biótica es el consumo por parte de los microorganismos heterótrofos y las plantas. Ritter et al. (2005) señalan que plantaciones de rápido crecimiento con una alta densidad tienen un mayor consumo de $\mathrm{N}$ debido a la alta demanda por parte de la vegetación. Contrariamente, en el bosque de $N$. obliqua desde la mitad de los meses de verano hasta fines de otoño se produjeron las mayores tasas de $\mathrm{N}$-min, para posteriormente disminuir, aspecto que podría estar relacionado con mayor aporte de hojarasca de caducifolias y su 
posterior descomposición. La inmovilización abiótica se relacionaría por ejemplo a la retención del $\mathrm{N}-\mathrm{NH}_{4}{ }^{+}$por las arcillas y la reacción química de $\mathrm{N}-\mathrm{NH}_{4}{ }^{+}$con la MOS, dependiente del $\mathrm{pH}$ del suelo. En este sentido, además del tipo de hojarasca, las características del suelo bajo $P$. radiata, tales como $\mathrm{pH}$, podría influir en una mayor tasa de inmovilización.

Las tasas mensuales de $\mathrm{N}$-min fueron siempre significativamente mayores en el bosque de $N$. obliqua que en la plantación. El balance en el suelo de $N$. obliqua fue $12.0 \mathrm{~kg}^{-1}$ $\mathrm{N} \mathrm{ha}^{-1}$ año $^{-1}$ y en la plantación $6.0 \mathrm{~kg}^{-1} \mathrm{~N} \mathrm{ha}^{-1}$ año ${ }^{-1}$, desde septiembre 2003 hasta agosto 2004. Valores similares fueron estimados por Pérez et al. (1998) y son comparativamente bajos comparados a valores registrados en bosques de regiones industrializadas (Perakis \& Hedin 2002). La mayor tasa de N-min del bosque de $N$. obliqua comparado con la plantación se podría atribuir a la diferencia en calidad de la hojarasca (variable no medida en este estudio), aun cuando las características recalcitrantes de las acículas de pino han sido señaladas por Schlatter \& Otero (1995). Según Johnson et al. (2000) y Ritter et al. (2005), la cantidad de $\mathrm{N}$ mineralizado en el suelo depende de muchos factores, aunque la calidad de la hojarasca es uno de los más importantes. La MOS y las diferencias interespecíficas en las propiedades de la hojarasca inciden en procesos locales de descomposición, mineralización y disponibilidad de nutrientes. Así la disponibilidad y el ciclo del $\mathrm{N}$ en los bosques puede ser afectado por el tipo de bosque y el manejo. Pérez et al. (2003) destacan la importancia de los ciclos internos de $\mathrm{N}$ como la primera y más importante fuente de $\mathrm{N}$ inorgánico para la productividad de los bosques prístinos. Según Fontaine et al. (2004), la tasa de crecimiento de los microorganismos es controlada por la disponibilidad de nutrientes en la MOS y en la solución de suelo. Borie et al. (2002), en estudios realizados en la región $\left(38^{\circ} 37^{\prime} \mathrm{S}, 7^{\circ} 04^{\prime} \mathrm{O}\right)$, señalan que el reservorio de $\mathrm{N}$ en el suelo varía de un 0,6 a 0,9\% de la materia seca del suelo, donde un 90 a $95 \%$ corresponde a distintas fracciones de $\mathrm{N}$ orgánico, porque los organismos del suelo son fundamentales para la biodisponiblidad de este elemento. Por otro lado, el bajo porcentaje de especies de hongos saprófitos en plantaciones de $P$. radiata indica escasa afinidad y, por tanto, baja degradación de MOS por especies nativas de Agaricales (Valenzuela et al. 1998).

En el suelo de $N$. obliqua y $P$. radiata se observó una tendencia estacional de la mineralización potencial de $\mathrm{C}$, en relación directa con periodos de mayor contenido de humedad del suelo y precipitación (marzo-mayo 2004 y marzo 2005). Conant et al. (1998), Six \& Jastrow (2002) y Carmona et al. (2006) han indicado que los factores de liberación de $\mathrm{CO}_{2}$ durante la descomposición de la MOS presentan a menudo la característica de estacionalidad, correlacionados positivamente con la precipitación anual y negativamente con temperaturas extremas. Los resultados del presente estudio muestran que el C-min del suelo en plantaciones de $P$. radiata fue significativamente menor que en el suelo de $N$. obliqua y reflejando una estrecha interacción entre C:N de la hojarasca, y las características del suelo. La vegetación afecta la tasa de producción del $\mathrm{CO}_{2}$ y produce diferencias en la calidad de la MO que se incorpora al suelo. Componentes fenólicos recalcitrantes, tales como lignina y taninos, inhiben la actividad de los microorganismos, retardando las tasas de descomposición y mineralización de la MOS (Ross 1996, Satti et al. 2003). De esta forma, la calidad del sustrato del bosque de $N$. obliqua influyó significativamente en la mayor liberación de $\mathrm{CO}_{2}$, comparado con el suelo el $P$. radiata.

Resultados similares a los del presente estudio son discutidos por Paul et al. (2002) en Australia, quienes compararon la producción de $\mathrm{CO}_{2}$ del suelo en un bosque de Eucalyptus con una plantación de $P$. radiata. La menor producción de $\mathrm{CO}_{2}$ en este último fue atribuida principalmente a la menor calidad de la hojarasca. Matteucci \& Paces (2000) y Cotrufo et al. (2000) indican que cualquier cambio en la vegetación original tiene el potencial para modificar la tasa de producción y liberación del $\mathrm{CO}_{2}$, existiendo una relación proporcional con una mayor diversidad de microorganismos, afirmación que podría ser relacionada con la correlación positiva de C-min con la actividad potencial FDA en el bosque de $N$. obliqua. Zahir et al. (2001) y Sicardi et al. (2004) también encontraron una alta correlación entre la actividad potencial FDA y la C-min, bajo diferentes coberturas vegetacionales. 
Huygens et al. (2005), para la misma área de estudio, indican que C-min en diferentes fracciones de la MOS fueron disminuyendo en relación al uso de los suelos en la secuencia: $N$. obliqua $>P$. radiata $>$ pradera. Experimentos sobre la fracción aislada de la MOS, muestran que la recalcitrancia de la MOS es mayor en $P$. radiata que en $N$. obliqua y el cambio de uso de suelo en Andisoles afecta la dinámica del C y la descomposición de la MOS, formando complejos órgano-minerales difíciles de degradar por los microorganismos. Dilly \& Munich (2001) y Satti et al. (2003) indican que la diversidad de microorganismos heterótrofos están fuertemente correlacionada con la calidad y cantidad del $\mathrm{C}$ orgánico en el suelo.

Cárcamo et al. (2004) obtuvieron valores similares de actividad potencial ureasa en el sitio de $N$. obliqua, y superiores a los registrados por Borie \& Fuentealba (1982) en suelos volcánicos de uso agrícola del centro y sur de Chile. Nuestros valores de ureasa en $N$. obliqua son mayores a los registrados en España bajo Quercus sp. (Leirós et al. 2000), factor que pudiera ser atribuido al clima y las características propias del suelo de esa región. Saviozzi et al. (2001), en estudios realizados en Italia en suelos cultivados, plantaciones y praderas naturales, encontraron una importante diferencia en la actividad potencial proteasa, ureasa y $\mathrm{C}$ orgánico, mostrando los mayores valores en ecosistemas no perturbados. Los valores de la proteasa registrados en el suelos de bosque de $N$. obliqua y bajo $P$. radiata son superiores a los registrados por este autor en bosques de Populus sp. y praderas naturales. Tendencias similares señala Dinesh et al. (2004) en el centro-oeste de España y el centrooeste de Italia y Haynes \& Knight (1989) en Nueva Zelanda, destacando la alta sensibilidad de estas enzimas a la cobertura de suelo y su relación con los ciclos de $\mathrm{N}$ y $\mathrm{C}$.

La correlación positiva entre las actividades potenciales de FDA y proteasa se debería a la participación de varias enzimas, no específicas en las hidrólisis del FDA, incluida la proteasa (Adam \& Duncan 2001, Green et al. 2005). Esta relación no se observaría en la plantación de $P$. radiata, como consecuencia de la diferencia en el tamaño y reservorio de microorganismos, dada las características de la hojarasca de $P$. radiata y la menor disponibilidad de nutrientes (Valenzuela et al. 1998). Sarathchandra et al.
(1989), Aon et al. (2001) y Sicardi et al. (2004) han obtenido datos similares en plantaciones de Eucalyptus grandis Hill ex Maiden y praderas artificiales en comparación a $P$. radiata.

Se concluye que las tasas de $\mathrm{N}$-min y C-min presentaron un comportamiento estacional, con los mayores montos en los meses de primaveraverano, mientras que las actividades enzimáticas del suelo no mostraron una clara estacionalidad. La conversión de los bosques naturales a plantaciones comerciales exóticas de rápido crecimiento produce un cambio en la química del suelo incrementando la relación $\mathrm{C}: \mathrm{N}$, resultando en una menor tasa de descomposición de la materia orgánica, y reducción de los procesos de mineralización $(\mathrm{C}, \mathrm{N})$ y la actividad biológica del suelo.

\section{AGRADECIMIENTOS}

Los autores agradecen las sugerencias del editor y árbitros, cuya contribución mejoró significativamente la presentación del manuscrito. Esta publicación es un aporte al FONDECYT 1030344. Los autores agradecen una beca doctoral de la Comisión Nacional de Ciencia y Tecnología a Y. Rivas y de la DID de la Universidad Austral de Chile.

\section{LITERATURA CITADA}

ADAM G \& H DUNCAN (2001) Development of a sensitive and rapid method for the measurement of total microbial activity using fluorescein diacetate (FDA) in a range of soils. Soil Biology \& Biochemistry 33: 943-951.

ALEF K \& P NANNIPIERI (eds) (1995) Methods in applied soil microbiology and biochemistry. Academic Press, London, United Kingdom. 576 pp.

AON M, M CABELLO, D SARENA, A COLANERI, M FRANCO, J BURGOS \& S CORTASSA (2001) I. Spatial-temporal patterns of soil microbial and enzymatic activities in an agricultural soil. Applied Soil Ecology 18: 239-254.

BERG B \& E MATZNER (1997) Effect of N deposition on decomposition of plant litter and soil organic matter in forest systems. Environmental Review 5: 1-25.

BORIE F \& R FUENTEALBA (1982) Bioquímica de suelos derivados de cenizas volcánicas. II. Actividad ureásica. Agricultura Técnica (Chile) 42: 135-141.

BORIE F \& H ZUNINO (1983) Organic matterphosphorus associations as a sink in P-fixation processes in allophanic soils of Chile. Soil Biology \& Biochemistry 15: 599-603

BORIE, G PEIRANO, P ZUNINO \& S AGUILERA (2002) $\mathrm{N}$-pool in volcanic ash-derived soils in Chile and its 
changes in deforested sites. Soil Biology \& Biochemistry 34: 1201-1206.

BREMNER J (1965) Inorganic forms of nitrogen. En: Black CA et al. (eds) Methods of soil analysis. Part 2: 1179-1273. Agronomical Monographs, American Society of Agronomy, Madison, Wisconsin, USA.

BUCH MW \& M OSORIO (1987) Probleme um die Pinus radiata - Monokulture in Südchile. Forstarchiv 58: 249-253

CÁRCAMO A, L PUENTES, R GODOY, C OYARZÚN \& E VALENZUELA (2004) Actividad biológica del suelo en un bosque de Nothofagus obliqua (Mirb.) Oerst., centro-sur de Chile. Revista de la Ciencia del Suelo y Nutrición Vegetal (Chile) 4: 14-25.

CARMONA R, M AGUILERA, C PÉREZ \& I SEREY (2006) Actividad respiratoria en el horizonte orgánico de suelos de ecosistemas forestales del centro y sur de Chile. Gayana Botanica 63: 1-12.

COTRUFO M, M MILLER \& B ZELLER (2000) Carbon and nitrogen cycling in European forest ecosystems. En: Schulze E-D (ed) Carbon and nitrogen cycling in European forest ecosystems: 257- 275. SpringerVerlag, Berlin, Germany

CORNELISSEN J (1996) An experimental comparison of leaf decomposition rates in wide range of temperate plant species and types. Journal of Ecology 84: 573 582.

CONANT R, M JEFFREY, R KLOPATEK, R MALIN \& C KLOPATEK (1998) Carbon pool and fluxes along an environmental gradient in northern Arizona. Biogeochemistry 43: 43-61.

DINESH R, M SURYANARAYANA, S GHOSHAL, T CHAUDHURI \& E SHEEJA (2004) Long-term influence of leguminous cover crops on the biochemical properties of a sandy clay loam Fluventic Sulfaquent in a humid tropical region of India. Soil and Tillage Research 77: 69-77.

DILLY O \& JC MUNCH (2001) Microbial biomass content, basal respiration and enzyme activities during the decomposition of leaf litter in a black alder (Alnus glutinosa (L.) Gaertn.) forest. Soil Biology \& Biochemistry 33: 921-930.

DONOSO C (1993) Ecología forestal. El bosque y su medio ambiente. Editorial Universitaria, Santiago, Chile. 309 pp

EMMET BA (2002) The Impact of nitrogen deposition in forest ecosystems: A Review. URL: http:// www.bangor.ceh.ac.uk/terrestrial-umbrella/reports/ forest review.pdf. (Accedido el 13 de octubre 2005).

FONTAINE S, A GÉRARD, D BENESTA, B VERDIERA, A MARIOTTIB \& L ABBADIEA (2004) Mechanisms of the priming effect in a savannah soil amended with cellulose. Soil Science Society American Journal 68: 125-131

FRANK D \& M FINCKH (1997) Impactos de las plantaciones de pino oregón sobre la vegetación y el suelo en la zona centro-sur de Chile. Revista Chilena de Historia Natural 70: 191-211.

GODOY R, C OYARZÚN \& V GERDING (2001) Precipitation chemistry in deciduous and evergreen Nothofagus forests of southern Chile under a lowdeposition climate. Basic \& Applied Ecology 2: 6572 .

GODOY R, J HANEKE, J STAELENS, C OYARZÚN, L PAULINO \& M BARRIENTOS (2005) Dry deposition of nitrogen in grassland and forest canopies in the central depression of southern Chile. Gayana Botanica 62 108-117.

GOH K \& S HENG (1987) The quantity and nature of the forest floor and topsoil under some indigenous forests and nearby areas converted to Pinus radiata plantations in South Island New Zealand. New Zealand Journal of Botany 25: 243-254.

GREEN V, D STOTT \& M DIACK (2006) Assay for fluorescein diacetate hydrolytic activity: Optimization for soil sample. Soil Biology \& Biochemistry 38: 693-701.

GUO L \& R GIFFORD (2002) Soil carbon stocks and land use change: a meta analysis. Global Change Biology 8: 345-360.

HAYNES R \& K KNIGHT (1989) Comparison of soil chemical properties, enzyme activities, levels of biomass $\mathrm{N}$ and aggregate stability in the soil profile under conventional and no-tillage in Canterbury, New Zealand. Soil \& Tillage Research 14: 197-208.

HEDIN L, J ARMESTO \& A JOHNSON (1995) Patterns of nutrient from unpolluted, old-growth temperate forest: evaluation of biogeochemical theory. Ecology 76: 493-509.

HUYGENS D, P BOECKX, O VAN CLEEMPUT, R GODOY \& C OYARZÚN (2005) Aggregate structure and stability linked to carbon dynamics in a south Chilean Andisol. Biogeosciences 2: 203-238.

INSTITUTO NACIONAL FORESTAL (INFOR) (2006) Plantaciones forestales. Instituto Forestal, Santiago, Chile. URL: http://www.chilenoticias.cl/ Comunicaciones_INFOR/Archivo_Noticias/2005/ Septiembre05/Noticias/mercado_forestal _n8_julio06.pdf.

JOHNSON D, W CHENG \& I BURKE (2000) Biotic and abiotic nitrogen immobilization. Soil Science Society of American Journal 64: 1503-1514.

LADD J \& J BUTLER (1972) Short-term assays of soil proteolytic enzyme activities using proteins and dipeptide derivatives as substrates. Soil Biology \& Biochemistry 4: 19-30.

LAMBERS H, F CHAPIN \& T PONS (1998) Plant physiological ecology. Springer-Verlag, New York, USA. 540 pp.

LEIRÓS M, C TRASAR-CEPEDA, S SEOANE \& F GILSOTRES (2000) Biochemical properties of acid soils under climax vegetation (Atlantic oakwood) in an area of the European temperate-humid zone (Galicia, NW Spain): general parameters. Soil Biology \& Biochemistry 32: 733-745.

LUGO A \& E BROWN (1993) Management of tropical soils as sinks or sources of atmospheric carbon. Plant \& Soil 149: 27-41

LUSK C, C DONOSO, M JIMÉNEZ, C MOYA, G OYARCE, R REINOSO, A SALDAÑA, P VILLEGAS \& F MATUS (2001) Descomposición de hojarasca de Pinus radiata y tres especies arbóreas nativas. Revista Chilena de Historia Natural 74: 705-710.

MATTEUCCI G \& PACES T (2000) Modelanalysis of carbon and nitrogen cycling in Picea and Fagus forests. En: Schulze E-D (ed) Carbon and nitrogen cycling in European forest ecosystems: 419-467. Springer-Verlag, Berlin, Germany

NANNIPIERI P (1994) The potential use of soil enzymes as indicators for productivity, sustainability and pollution. En: Pankhurst CE, BM Doube, VVSR Gupta \& PR Grace (eds) Soil biota management in sustainable farming systems: 238-244. CSIRO, Adelaide, Australia.

OYARZÚN C, C ARACENA, P. RUTHERFORD, R GODOY \& A DESCHRIJVER (2007) Effect of land use conversion from native forests to exotic plantations on streamwater quality in southern 
Chile. Water, Air \& Soil Pollution 179: 341-350.

PAUL K, P POLGLASE, J NYAKUENGAMA \& P KHANNA (2002) Change in soil carbon following afforestation. Forest Ecology \& Management 168: 241-257.

PERAKIS S, J COMPTON \& L HEDIN (2005) Nitrogen retention across a gradient of ${ }^{15} \mathrm{~N}$ additions to an unpolluted temperate forest soil in Chile. Ecology 86: 96-105.

PERAKIS S \& L HEDIN (2002) Nitrogen loss from unpolluted South America forests mainly via dissolved organic compounds. Nature 415: 416-419.

PÉREZ C, L HEDIN \& J ARMESTO (1998) Nitrogen mineralization in two unpolluted old-growth forest of contrasting biodiversity and dynamics. Ecosystems 1: 361-373.

PÉREZ C, M CARMONA \& J ARMESTO (2003) NonSymbiotic nitrogen fixation, net nitrogen mineralization and denitrification in evergreen forest of Chiloé island, Chile: A comparison with other temperate forest. Gayana Botanica 60: 25-33.

PÉREZ C, M CARMONA, J ARAVENA \& J ARMESTO (2004) Succesional changes in soil nitrogen availability, non-symbiotic nitrogen fixation and carbon/nitrogen ratios in southern Chilean forest ecosystems. Oecologia 140: 617-625.

PIIRAINEN S, L FINÉR, H MANNERKOSKI \& M STARR (2002). Effects of clear-cutting on the carbon and nitrogen fluxes through podzolic soil horizons. Plant \& Soil 239: 301-311.

RAISON, R, M CONNELL \& P KHANNA (1987) Methodology for studing fluxes of soil mineral-N in situ. Soil Biology \& Biochemistry 19: 521-530.

RITTER E, M STARR \& L VESTERDAL (2005) Losses of nitrate from gaps of different sizes in a managed beech (Fagus sylvatica) forest. Canadian Journal of Forest Research 35: 308-319.

ROSS D, K TATE \& W FELTHAM (1996) Microbial biomass, and $\mathrm{C}$ and $\mathrm{N}$ mineralization, in litter and mineral soil of adjacent montane ecosystems in a southern beech (Nothofagus) forest and a tussock grassland. Soil Biology \& Biochemistry 28: 16131620 .

SARATHCHANDRA S, U PERROTT \& K LITTLER (1989) Soil microbial biomas: Influence of simulated temperature changes on size, activity and nutrient-content. Soil Biology \& Biochemistry 21: 987-993.

SATTI P, M MAZZARINO, M GOBBI, F FUNES \& L ROSELLI (2003) Soil N dinamics in relation to leaf litter quality and soil fertility in north-western Patagonian forests. Journal of Ecology 91: 173-181.

SAVIOZZI A, R LEVI-MINZI, R CARDELLI \& R RIFFALDI (2001) A comparation of soil quality in adjacent cultivated, forest and native grassland soils. Plant \& Soil 233: 251-259.

SCHLATTER J \& L OTERO (1995) Efecto de Pinus radiata sobre las características químicas-nutritivas del suelo mineral superficial. Bosque (Chile) 16: 29-46.

SCHNÜRER J \& T ROSSWALL (1982) Fluorescein diacetate hydrolysis as a measure of total microbial activity in soil and litter. Applied and Environmental Microbiology 43: 1256-1261.

SICARDI M, F GARCÍA \& L FRIONIC (2004) Soil microbial indicators sensitive to land use conversion from pastures to commercial Eucalyptus grandis (Hill ex Maiden) plantations in Uruguay. Applied Soil Ecology 27: 125-133.

SIX J \& J JASTROW (2002) Organic matter turnover. En: R. Lal (ed) Encyclopedia of Soil Science 936-942. Marcel Dekker, New York, USA.

STAELENS J, A DE SCHRIJVER, C OYARZÚN \& N LUST ( 2003) Comparison of dry deposition and canopy exchanges of base cations in temperate hardwood forest in Flanders and Chile. Gayana Botanica 60: 9-16.

STEUBING L, R GODOY \& M ALBERDI (2002) Métodos de ecología vegetal. Editorial Universitaria, Santiago, Chile. 345 pp.

TAYLOR B, R PARKINSON, D PEARSONS (1989) Nitrogen and lignin content as predictors of litter decay rates: a microcosm test. Ecology 70: 97-104.

TOSsO J (ed) (1985) Suelos volcánicos de Chile. Ministerio de Agricultura, Instituto de Investigaciones Agropecuarias, Santiago, Chile. 723 p.

VALENZUELA E, S LEIVA, \& R GODOY (1998) Micosociología en bosques de Nothofagus y plantaciones de Pinus radiata en la X Región de Chile: diversidad y rol ecológico. Revista Chilena de Historia Natural 71: 133-146.

VALENZUELA E, S LEIVA \& R GODOY (2001) Variación estacional y potencial enzimático de microhongos asociados con la descomposición de hojarasca de Nothofagus pumilio. Revista Chilena de Historia Natural 74: 737-749.

WEATHERS K, G LOVETT, G LIKENS \& N CARACO (2000) Cloudwater inputs of nitrogen to forest ecosystems in southern Chile: frm, fluxes, and sources. Ecosystems 3: 590-595.

WILL G (1985) Nutrient deficiencies and fertilizer use in New Zealand exotic forests. Bulletin $\mathrm{N}^{\circ}$ 97. Rotorua, Forest Research Institute, New Zealand. 53 pp.

ZAR JH (1996) Biostatistical analysis. Third edition. Prentice-Hall, Inc., Englewood Cliffs, New Jersey, USA. $662 \mathrm{pp}$.

ZAHIR A, A MUHAMMAD, R MALIK \& M ARSHAD (2001) Soil enzymes research: a review. Journal of Biological Sciences 1: 299-307.

ZHANG Y, N WU, G ZHOU \& W BAO (2005) Changes in enzyme activities of sprunce (Picea balfouriana) forest soil as related to burning in the eastern Qinghai-Tibetan plateau. Applied Soil Ecology 30: 215-225. 